\title{
Health Care and Hospitalisation Costs of Cardiovascular Disease (CVD) in Thailand
}

\author{
R. Inthawong1, K. Khatab ${ }^{2,3}$, M. Whitfield ${ }^{2}$, K. Collins' ${ }^{2}$, M. Raheem ${ }^{4}$, M. Ismail2 \\ ${ }^{1}$ Department of Public Health, Loei Rajabhat University, Loei, Thailand \\ ${ }^{2}$ Faculty of Health and Wellbeing, Sheffield Hallam University, Sheffield, UK \\ ${ }^{3}$ Department of Arts and Sciences, Ohio University, Zanesville, OH, USA \\ ${ }^{4}$ Departments of Engineering and Mathematics, Sheffield Hallam University, Sheffield, UK \\ Email: *k.khatab@shu.ac.uk
}

How to cite this paper: Inthawong, R., Khatab, K., Whitfield, M., Collins, K., Raheem, M. and Ismail, M. (2019) Health Care and Hospitalisation Costs of Cardiovascular Disease (CVD) in Thailand. Open Access Library Journal, 6: e5320.

https://doi.org/10.4236/oalib.1105320

Received: March 8, 2019

Accepted: March 24, 2019

Published: March 27, 2019

Copyright $\odot 2019$ by author(s) and Open Access Library Inc.

This work is licensed under the Creative Commons Attribution International License (CC BY 4.0).

http://creativecommons.org/licenses/by/4.0/

\begin{abstract}
Background: Cardiovascular disease (CVD) has become a leading cause of death and disability in Thailand due to the unhealthy lifestyle of the populace; triggering high risk of exposure to CVD, and increased the number of hospital admissions year on year. Objectives: The concerns generated by the inflation in the health care expenditure among service providers motivated this study to examine the costs of hospitalisation of inpatients with (CVD) conditions in Thailand, 2009. Methods: Anonymised secondary data of 327,435 CVD inpatients under "Universal Coverage" (UC) health care scheme were obtained from the National Health Security Office (NHSO), Thailand. The data $(51.69 \%$ women and $48.31 \%$ men) were classified using International Classification of Diseases, Tenth Revision (ICD-10) code, of which I20 - I25 are Ischemic heart disease (IHD), I60 - I69 are stroke and I00 - I99 are all CVD conditions. Results: Average costs of treatments for all CVD conditions, IHD and stroke were $\mathbb{B} 21,921(\mathfrak{E} 1=\mathbb{B} 50)$, $\mathbb{B} 32,884$ (highest) and $\$ 25617.67$ per patient respectively. Absolute total cost increased with age and the cost of admission of male patients is higher than female. The average (three months) length of stay for stroke patients was found to be the highest. Conclusion: Providers generally spent a total of B7177 million on the treatment of CVD with IHD and stroke taking B2544 million and B1920 million respectively.
\end{abstract}

\section{Subject Areas}

Epidemiology

\section{Keywords}

Cardiovascular Disease (CVD), Universal Coverage (UC), Ischemic Heart Disease (IHD), Stroke, Length of Stay (LOS), Cost of Treatment 


\section{Introduction}

Over the past decade, CVD has been one of the leading causes of premature death and disability and has become a burden in Thailand [1]. As a result of Thailand's urbanisation the peoples' lifestyles have changed, such as a decrease in the level of physical activities, changing their dietary patterns and habits which increase metabolic risk factors such as BMI, total cholesterol and blood pressure [2] [3] [4] [5] [6].

The National Health Security Office, Thailand reported that the number of hospital admissions which are caused by CVD conditions has continuously increased and has tripled since 1992 [7]. This has not only increased the number of the hospital admissions but has also affected the loss of productivity due to absence from work, a decline in the quality of life and increased health care expenditure, of both health care services providers and the patients' families. In 2007, Thailand spent $\$ 36.5$ million on inpatients medical care for non-communicable diseases, of which $10 \%$ of this expenditure was attributable to CVD [8].

There were several studies on the health care cost of CVD in Thailand. In 2007, the median cost of treatment for acute coronary syndrome (ACS) patients was $B 47,908(\mathfrak{E} 1=B 50)$. However, the cost of treatment varied depending on the diagnosis group, treatment procedures and the complication of the diseases [9]. The annual hospital charges for the treatment of multiple chronic conditions varied from B611 to B16,794, depending on the health status and severity of the disease in the patient [10]. Some studies estimated the medical costs attributable to risk factors such as cigarette smoking and obesity. The average direct out-of-pocket cost of CHD which was attributable to smoking was estimated at $B 33716.40$ per patient or B1773.68 million in total [11]. The total economic cost attributable to obesity has been estimated at B2168.4 million spending on IHD and B2017.6 million spending on stroke, which includes health care costs, cost of premature death and the cost of productivity loss due to hospital-related absenteeism [12].

Regarding the cost of stroke rehabilitation, it was found that stroke patients spent, on average $B 11170.56 \pm 5641.73$ per patient at the medical rehabilitation [13]. Additionally, out of pocket expenses of stroke patients occur when they need informal care, which is usually provided by their family, friends or neighbours. The cost of informal care for stroke patients has been estimated at B4642.6 per month, based on 2006 prices.

The average time spent on the national care of stroke patients was 94.6 hours, which implies that there is a loss of opportunity costs which are forgone because unpaid work was undertaken in caring for the patient [14]. Although it is already known that CVD has become an economic burden in Thailand, there were limited studies focused on how to tackle this issue. This study, however, aimed to investigate the national level of the total cost of CVD for Thailand during 2009.

\section{Methods}

This is a prevalence-based study of the health care expenditure of CVD in-patients 
in Thailand, 2009. In this study, CVD is defined according to the international classification of diseases 10th version (ICD-10) [15]. The CVD conditions have been classified and analysed by the ICD-10 codes of which I20 to I25 refers to ischemic heart diseases, I60 to I69 refer to stroke and I00 to I99 relate to all CVD conditions.

\subsection{Data Sources}

The health care costs of CVD have been analysed using data from the inpatient's services in Thailand in 2009-2010. The numbers and the costs of the anonymous inpatient data were obtained from the National Health Security Office (NSO) [7], Thailand. This data includes the inpatient hospital admissions in the Universal Coverage Health Care Scheme (UC), which is the primary health care insurance system in Thailand. Approximately 47.24 million of the population or $75.29 \%$ of the total population of 64 million are in the UC scheme. The health care services cover 11,460 health care units nationwide, which include public hospitals managed under the ministry of public health, other public hospitals, private hospitals and sub-district health promoting hospitals.

\subsection{Data Collection}

The number of hospital admissions and the cost of hospitalisation were obtained from the National Health Security Office (NHSO), Thailand [7]. A formal letter, research protocol, dummy tables, plans for data analysis and the data requested form were submitted to the NHSO during September 2013. The data permission was approved in May 2014. The use of the anonymous hospitalisation data is controlled under the criteria of the data sharing policy from NHSO, Thailand.

Data verification and preparation: The ICD-10 code has classified the anonymous CVD inpatients data. A descriptive analysis of all variables in the data set has been performed to look at data coding, frequency and the distribution of data. If the total cost, the length of stay and the average cost per day is inconsistent, those records will be recorded as missing. The continuous variables such as the length of stay and total costs have been checked for the outlier values. The outliers of the total cost of hospitalisation data have been identified by calculating the cost of hospital admissions per day. The minimum cost of hospital admission was set at $\$ 500$ per day ( $£ 10$ per day) [7], which was the minimum amount a patient usually pay at the point of admission into a public hospital. The maximum cost of hospital admission was up to $\$ 65,000$ per day ( $£ 1300$ per day), which was the maximum possible cost if the patients received a specialist medical procedure or were admitted to an intensive care unit (ICU).

\subsection{Health Care Cost}

The focus of this study is basically on the health care service providers' perspective. The total cost of treatment and hospitalisation included both direct medical cost and direct non-medical cost such as; room rates and meals, the prosthesis, 
medical devices used in treatment, medication that was used in hospitals, the medical diagnosis, the clinical resources, therapeutic radiology, medical equipment, medical procedure fees, nursing services, physical and rehabilitation services in hospital, other specialist diagnostic methods, and the other treatments from health professionals. However, since the patients' perspectives are not considered in this study, the indirect costs such as the cost of productivity loss due to absence from work, costs on patients and their family out of pocket expenses are not included in the analysis.

\subsection{Statistical Analysis}

The descriptive statistics present the overall health care costs of CVD, in mean and absolute total costs of hospital admissions. The unit of hospitalisation cost will be presented in Thai Baht $(\mathfrak{E 1}=\mathbb{B} 50)$. The total cost of hospital admissions will be calculated by multiplying the number of CVD patients by the average cost of hospital admission per patient. The statistical analysis has been carried out using a STATA software version 14 [16].

Ethical approval: This study has used secondary data and this why ethical approval was not needed. However, Health Care organisation in Thailand has allowed us to access these datasets (the hospitalisation data from the social security health insurance system, and the civil servant health insurance system).

\section{Results}

Table 1 shows the number and percentage of the 327,435 patients who had a primary diagnosis with CVD conditions (ICD-10, I00 - I99), classified by CVD condition, age group, gender, length of stay and the discharge status.

Of the 327,345 patients, $23.6 \%$ had Ischemic heart disease (IHD), $22.9 \%$ had a stroke, and 53.5\% had other CVD conditions. The number of CVD inpatients increased respectively by age groups but slightly decreased at age 75 years and over. The number of IHD and stroke patients was high in the middle and elderly age groups, with the number of patients increasing at age 45 - 54 years and reach the highest at age $65-74$ years. Although the number of CVD inpatients in the younger age groups 15 - 24 years and 25 - 34 years was lower than in the older age groups, the proportion of patients who had other CVD conditions was higher than the older age groups. The results show that at age $15-24$ years, of 4706 patients, $3.1 \%$ had IHD, $12.8 \%$ had a stroke and $84.2 \%$ had other CVD conditions. While at age $55-64$ years, of 74,073 patients, half of them had IHD and stroke and half of them had the other CVD conditions.

When comparing between genders, the number of inpatients with IHD and stroke in men was higher than in women. Conversely, the number of patients with other CVD conditions was higher in women than in men. However, overall more women were admitted to the hospital with CVD conditions than men.

When classifying patients by the length of stay, patients with CVD a condition were mostly admitted to hospital for less than one month. $24 \%$ of patients in this 
Table 1. Number and percentage of CVD patients classified by CVD conditions, Universal Coverage Health Care Scheme (UC), Thailand 2009.

\begin{tabular}{|c|c|c|c|c|}
\hline Categories & IHD & Stroke & Other CVD & All CVD \\
\hline \multicolumn{5}{|l|}{ Age } \\
\hline $15-24$ & $146(3.1 \%)$ & $600(12.8 \%)$ & $3960(84.2 \%)$ & $4706(100 \%)$ \\
\hline $25-34$ & $614(7.3 \%)$ & $1266(15 \%)$ & $6549(77.7 \%)$ & $8429(100 \%)$ \\
\hline $35-44$ & $3483(14.2 \%)$ & $4774(19.4 \%)$ & $16,337(66.4 \%)$ & $24,594(100 \%)$ \\
\hline $45-54$ & $10,997(20.9 \%)$ & $12,211(23.3 \%)$ & $29,317(55.8 \%)$ & $52,525(100 \%)$ \\
\hline $55-64$ & $19,945(26.9 \%)$ & $16,902(22.8 \%)$ & $37,226(50.3 \%)$ & $74,073(100 \%)$ \\
\hline $65-74$ & $23,894(27.6 \%)$ & $20,129(23.3 \%)$ & $42,475(49.1 \%)$ & $86,498(100 \%)$ \\
\hline$\geq 75$ & $18,314(23.9 \%)$ & $19,067(24.9 \%)$ & $39,299(51.2 \%)$ & $76,610(100 \%)$ \\
\hline \multicolumn{5}{|l|}{ Gender } \\
\hline Men & $42,692(27 \%)$ & $40,736(26 \%)$ & $74,768(47 \%)$ & $158,196(100 \%)$ \\
\hline Women & $34,701(21 \%)$ & $32,213(20 \%)$ & $100,325(59 \%)$ & $169,239(100 \%)$ \\
\hline \multicolumn{5}{|l|}{ Lengths of stay } \\
\hline$<1$ month & $76,720(24 \%)$ & $72,289(22 \%)$ & $173,487(54 \%)$ & $322,496(100 \%)$ \\
\hline$\geq 1-3$ months & $646(15 \%)$ & $2290(52 \%)$ & $1502(34 \%)$ & $4438(100 \%)$ \\
\hline$\geq 3$ - 6 months & $22(6 \%)$ & $281(71 \%)$ & $92(23 \%)$ & $395(100 \%)$ \\
\hline$\geq 6$ - 9 months & $1(1.6 \%)$ & $56(84.9 \%)$ & $9(13.6 \%)$ & $66(100 \%)$ \\
\hline$\geq 9-12$ months & $2(15.4 \%)$ & $9(69.2 \%)$ & $2(15.4 \%)$ & $13(100 \%)$ \\
\hline Unspecified & $2(7.4 \%)$ & $24(88.9 \%)$ & $1(3.7 \%)$ & $27(100 \%)$ \\
\hline \multicolumn{5}{|l|}{ Discharge status } \\
\hline Complete recovery & $247(21.2 \%)$ & $154(13.2 \%)$ & $762(65.5 \%)$ & $1163(100 \%)$ \\
\hline Improve & $4988(23.7 \%)$ & $4949(20.1 \%)$ & $153,859(56.2 \%)$ & $273,787(100 \%)$ \\
\hline Not improve & $7162(23.1 \%)$ & $10,492(33.9 \%)$ & $131,315(42.9 \%)$ & $30,969(100 \%)$ \\
\hline Died & $4969(23.2 \%)$ & $9340(43.7 \%)$ & $7090(33.1 \%)$ & $21,399(100 \%)$ \\
\hline Unspecified & $27(23.1 \%)$ & $23(19.7 \%)$ & $67(57.3 \%)$ & $117(100 \%)$ \\
\hline Total & $77,393(23.6 \%)$ & $74,949(22.9 \%)$ & $175,093(53.5 \%)$ & $327,435(100 \%)$ \\
\hline
\end{tabular}

group were admitted with IHD, 22\% admitted with stroke and 54\% admitted with other CVD conditions. However, there were 4438 in patients who were admitted between 1 to 3 months, 52\% of them admitted with a stroke, $15 \%$ admitted with IHD and $34 \%$ admitted with other CVD conditions. Additionally, patients who were admitted to the hospital for more than three months were mostly stroke patients.

For the discharge status, 273,787 patients had improved from their illness when discharged from the hospital. 23.7\% of them improved from IHD, $20.1 \%$ improved from stroke and 56.2\% improved from the other CVD conditions. 1163 patients had complete recovery after being admitted to the hospital of which $21.2 \%$ recovered from IHD, $13.2 \%$ of them recovered from a stroke and 
65.5\% recovered from the other CVD conditions. However, 30,969 patients did not improve from their illness, and 21,399 patients were discharged because they died in hospital.

Table 2 shows the absolute total cost of hospital admissions by categories and CVD conditions. Overall, CVD patients cost B7199 million ( $£ 143$ million) of which IHD patients cost $\$ 2531$ million ( $£ 50$ million), stroke patients cost $\$ 1907$ million ( $£ 38$ million), and the other CVD conditions cost $\$ 2680$ million ( $£ 53$ million). The absolute total cost increased with each increasing age group but slightly decreased at the age of 75 years and over. When compared between genders, male patients had an absolute total cost of hospital admission more than women, which was B3888 million ( $£ 77$ million) in men and B3231 million ( $£ 64$ million) in women. The health care costs of treating men with IHD and stroke are higher than women. Conversely, the costs of treating women with

Table 2. Absolute Total Cost of Hospital Admission by Categories and CVD Condition (THB $\left.(\text { B })^{*}\right)$.

\begin{tabular}{|c|c|c|c|c|}
\hline Categories & IHD & Stroke & Other CVD & All CVD \\
\hline \multicolumn{5}{|l|}{ Age groups } \\
\hline $15-24$ & $2,257,119$ & $27,325,711$ & $79,120,065$ & $108,702,894$ \\
\hline $25-34$ & $14,390,400$ & $37,450,052$ & $127,964,733$ & $179,805,186$ \\
\hline $35-44$ & $108,533,174$ & $141,845,311$ & $319,239,325$ & $569,617,811$ \\
\hline $45-54$ & $380,368,138$ & $325,286,934$ & $532,507,274$ & $1,238,162,346$ \\
\hline $55-64$ & $744,748,695$ & $419,013,435$ & $579,576,458$ & $1,743,338,588$ \\
\hline $65-74$ & $814,269,234$ & $489,638,746$ & $582,287,556$ & $1,886,195,536$ \\
\hline $75+$ & $466,645,916$ & $466,828,809$ & $460,208,145$ & $1,393,682,870$ \\
\hline \multicolumn{5}{|l|}{ Gender } \\
\hline Men & $1,532,931,439$ & $1,038,994,870$ & $1,316,312,781$ & $3,888,239,089$ \\
\hline Women & $998,281,238$ & $868,394,128$ & $1,364,590,777$ & $3,231,266,142$ \\
\hline \multicolumn{5}{|l|}{ Length of stay } \\
\hline$<1$ month & $2,353,265,367$ & $1,261,968,543$ & $2,328,073,213$ & $5,943,307,123$ \\
\hline$\geq 1$ - 3 months & $159,254,375$ & $462,529,711$ & $297,183,150$ & $918,967,236$ \\
\hline$\geq 3-6$ months & $15,696,554$ & $129,767,646$ & $44,386,186$ & $189,850,386$ \\
\hline$\geq 6$ - 9 months & 573,153 & $28,518,983$ & $9,063,731$ & $38,155,866$ \\
\hline$\geq 9-12$ months & $1,883,622$ & $6,503,539$ & $1,716,157$ & $10,103,318$ \\
\hline \multicolumn{5}{|l|}{ Discharge status } \\
\hline Complete recovery & $8,020,575$ & $3,389,411$ & $17,132,857$ & $28,542,843$ \\
\hline Improve & $2,215,026,299$ & $1,268,554,308$ & $2,227,019,320$ & $5,710,599,928$ \\
\hline Not improve & $77,724,478$ & $164,419,209$ & $134,613,690$ & $376,757,378$ \\
\hline Died & $229,479,019$ & $470,848,354$ & $301,279,921$ & $1,001,607,294$ \\
\hline Total & $2,531,212,676$ & $1,907,388,998$ & $2,680,903,557$ & $7,119,505,231$ \\
\hline
\end{tabular}

*Note: $(\mathfrak{E 1}=\mathbf{B} 50)$. 
other CVD conditions are higher than those spent on men. The graph which compares the absolute total costs by age groups, gender and CVD conditions is presented in Figure 1 and Figure 2. Concerning the length of stay, the absolute total health care cost was highest in patients who were admitted to the hospital for less than one month because the number of patients in this group was higher than the other groups. The total cost spent on patients who had IHD and were admitted to the hospital for less than one month was $\$ 2353$ million ( $£ 47$ million). Patients with stroke and admitted to the hospital for less than one month cost B1261 million ( $£ 25$ million). Additionally, patients with other CVD conditions cost as much as IHD patients, which was $\$ 2328$ million ( $£ 46$ million). Furthermore, patients who were admitted between 9 to 12 months had a higher absolute total cost than patients who were admitted between 1 and up to 9 months.

When classified by the discharge status, the highest absolute health care cost was in patients who improve from illness, which cost B5710 million ( $£ 114$ million) in total, of which $\$ 2215$ million ( $£ 44$ million) was spent on IHD patients, and B1268 million ( $£ 25$ million) spent on stroke patients, and B2227 million ( $£ 44$ million) spent on other CVD patients. However, the total cost of hospital admissions was higher in patients who died from CVD. Some other studies that focused on other countries in Asia came up with different figures [17] [18] [19] [20] [21]. Table 3 shows a summary of the total cost of hospitalisation by CVD conditions in 2009. There were 327,435 CVD patients admitted to the hospital under the UC health care scheme. 77,393 patients were admitted for IHD, 74,949 patients were admitted for stroke, and 175,093 patients were admitted for the other CVD conditions.

The average length of stay was highest in stroke patients which were 6.72 days, IHD patients stayed in hospital on average 4.12 days, while patients who had other CVD conditions stayed in hospital on average 3.99 days. The average cost per day was highest in IHD patients, which cost B10,681 per day and second highest in stroke patients which cost B4067 per day, while the other CVD conditions cost $B 3614$ per day.

The average cost per patients was highest in IHD patients, stroke and other CVD respectively. IHD patients cost on average $B 32,884$, stroke patients cost on average $B 25,617$, and the other CVD patients cost on average $B 15,465$.

Table 3. Summary of the total cost of hospitalisation by CVD conditions in 2009.

\begin{tabular}{cccccc}
\hline CVD Conditions & $\begin{array}{c}\text { Total number of } \\
\text { cases }\end{array}$ & $\begin{array}{c}\text { The average length of Average cost per day } \\
\text { stay (days) }\end{array}$ & $\begin{array}{c}\text { Average cost per } \\
\left.\text { patient (THB }{ }^{*}\right)\end{array}$ & $\begin{array}{c}\text { Total cost (THB*) } \\
=(\text { number of cases } \times \\
\text { average cost per patients) }\end{array}$ \\
\hline IHD (I20 - I25) & 77,393 & 4.12 & 10,681 & 32,884 & $2,544,991,412$ \\
Stroke (I60 - I69) & 74,949 & 6.72 & 4067 & 25,617 & $1,920,018,748$ \\
other CVD & 175,093 & 3.99 & 3614 & 15,465 & $2,707,858,769$ \\
All CVD (I00 - I99) & 327,435 & 4.65 & 5393 & 21,921 & $7,177,705,909$ \\
\hline
\end{tabular}

${ }^{*}$ Note: $(\mathfrak{£} 1=$ B50 $)$. 


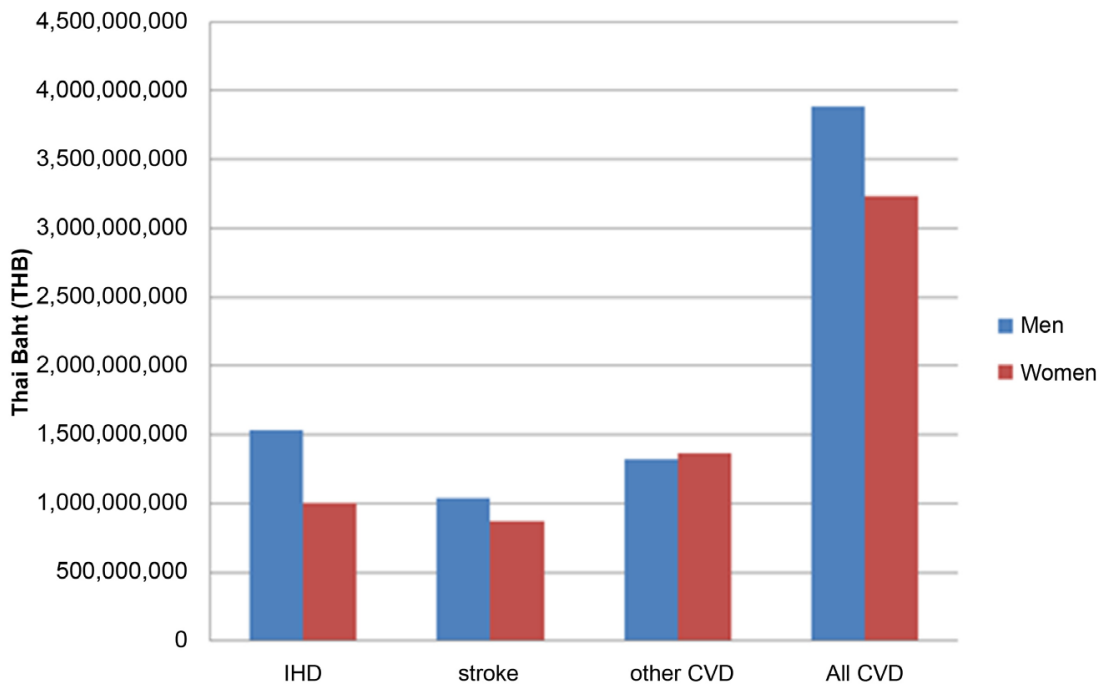

Figure 1. The absolute total cost of hospital admission by gender and CVD conditions, Thailand 2009 (THB).

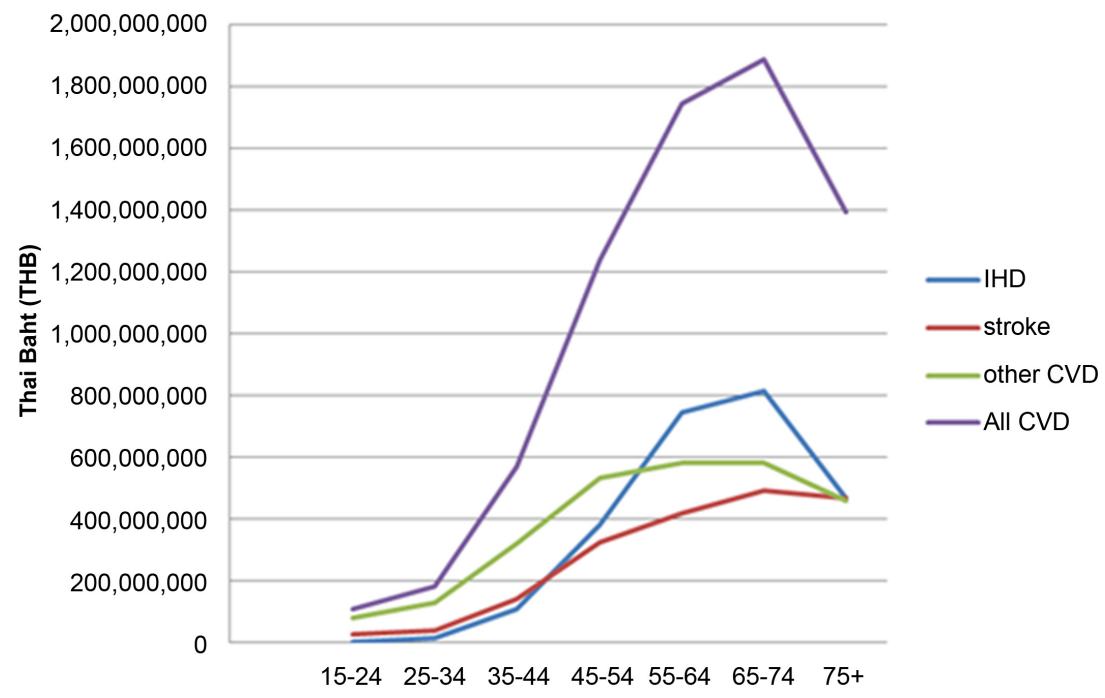

Figure 2. The absolute total cost of hospital admission by age group gender and CVD condition.

The total cost of the IHD was $B 2544$ million, and the total cost of stroke was B1920 million. The total cost of the other CVD conditions was B2707 million, which was higher than IHD and stroke.

Overall, the CVD patients admitted to the hospital stayed on average 4.65 days, the average cost per day was $B 5393$, and the average cost per patients was B21,921. The health service providers spent in the total of $B 7177$ million on the treatment of CVD.

\section{Discussion}

\subsection{Findings}

Although this analysis was focused only on patients covered under the UC 
health care scheme, it covered the majority $(75.29 \%)$ of the total population. The other health care schemes that were not included in the analysis were the Social Security (SS) health care scheme, which covered $15.42 \%$ of the population and the Civil Servant (CS) health care scheme which covers $8.2 \%$ of the population. Another limitation is that it covers mainly public hospitals, as only 60 private hospitals had been enrolled in the UC health care scheme. Therefore, the cost of hospital admission for CVD may underestimate the cost of hospital admission in a private hospital because the cost of treatment in a private hospital may be more expensive

Considering the health care costs by age groups, the absolute total health care cost was higher in the middle to elderly age groups because the number of cases was higher than younger age groups. Although the younger age groups had lower numbers of hospital admissions, when exploring the primary diagnosis of 15 to 24 years age group, it was found that majority of patients at age 15 to 24 had been diagnosed with other CVD conditions such as arthritis, heart failure, hypotension, endocarditis etc.

Hence, $1.44 \%$ of CVD inpatients were in this age group. When comparing the health care cost by discharge status, it was found that patients who died from CVD had the highest expenditure compared to those who completely recovered and those who did not recover or improve. This was because the patients who died were more likely to have stayed in the hospital longer than patients in the other groups.

When investigating the average length of stay by discharge status, it was found that patients who died from CVD had an average length of stay 7.23 days.

While patients who improved from CVD after admission to hospital stayed on average 4.6 days and patients who completely recovered from CVD stayed on average 4.05 days. On the other hand, patients who did not improve from CVD stayed on an average of 3 days.

Although the average cost per patients in the other CVD conditions is lower than IHD and stroke, the total cost of other CVD conditions was at the highest at B2707 million, because the number of total cases in this group is higher than IHD and stroke. However, IHD and stroke have a higher cost per patient.

\subsection{What Is Already Known on This Topic and What This Study Adds?}

Although it is already known that CVD has become an economic burden in Thailand and other Asian countries [22]-[27], the studies on the costs of hospital admissions are not up to date and are mostly limited to single health care units or individual groups. To the best of the author's knowledge, this is the first study that focused on healthcare and hospitalisation costs of CVD, IHD, and Stroke in Thailand. The benefit of this analysis is the capability to estimate the future occurrence of CVD events and the associated costs based on the currently available information and the scientific evidence, instead of following-up people over a long period. 
This study provides the information for the health policy developers to plan and invest in primary prevention programs for chronic diseases such as CVD, IHD, and Stroke rather than waiting until the problems occur or the prevalence of CVD increases in the population.

\subsection{Limitations}

This analysis focused only on the total expenditure that occurred when patients were admitted to the hospital. So, it was only from a health service provider perspective. There may have been hidden costs occurring when the patients were discharged from the hospital. They may have needed long-term care and rehabilitation. The patients and their families might have incurred some out of pocket costs such as the productivity loss, time lost due to work absenteeism, did not form part of this study because there were limitations in accessing the data. Furthermore, there was a limitation of the dataset which did not provide the information on the type of medical procedures that had been used for treatment, which may affect the cost of hospitalisation when patients required specialist treatments.

\section{Conclusion}

In conclusion, this study found that CVD had a significant impact on the hospitalization costs and economic burden in Thailand. In 2009, the health service providers spent $B 7177$ million on hospital admissions due to CVD conditions. The total expenditure for IHD patients was B2544 million and for stroke patients was $B 1920$ million.

\section{Recommendation}

Future research should investigate health care expenditure from the patient's perspective because CVD patients require long-time care. There are many hidden and out-of-pocket costs that occur with patients and their familybut few studies have been undertaken in Thailand.

\section{Acknowledgements}

The authors would like to express gratitude to the National Health Security Office (NHSO), Thailand for providing us with the data used for this research. We are also grateful to the reviewers for their efforts at ensuring this paper meet the required standard for publication in this journal.

\section{Funding}

There was no fund allocated for this study.

\section{Conflicts of Interest}

The author(s) declared no potential conflicts of interest concerning this study, authorship, and/or publication of this article. 


\section{References}

[1] International Health Policy Program (2009) Burden of Disease and Injury in Thailand 2004. Ministry of Public Health, Thailand.

[2] Aekplakorn, W., Sangthong, R., Kessomboon, P., Putwatana, P., Inthawong, R., Taneepanichskul, S., Sritara, P., Sangwatanaroj, S., Chariyalertsak, S. and National Health Examination Survey (NHES) IV Study Group (2012) Changes in Prevalence, Awareness, Treatment and Control of Hypertension in the Thai Population, 2004-2009: Thai National Health Examination Survey III-IV. Journal of Hypertension, 30, 1734-1742. https://doi.org/10.1097/HJH.0b013e3283568158

[3] Satheannoppakoa, W., et al. (2010) Dietary Consumption Patterns of Thai Population: The 4th Thailand NHES. Ramathibodi Medical Journal, 33, 144-145.

[4] Chongsuvivatwong, V., Yipintsoi, T., Suriyawongpaisal, P., Cheepudomwit, S., Aekplakorn, W., Faramnuayphol, P., Tatsanavivat, P., Kosulwat, V., Thamthitiwat, S. and Nuntawan, C. (2011) Comparison of Cardiovascular Risk Factors in Five Regions of Thailand: InterASIA Data. Journal of the Medical Association of Thailand, 93, 17-26.

[5] Stolk, R.P., Suriyawongpaisal, P., Aekplakorn, W., Woodward, M., Neal, B. and InterASIA Collaborative Group (2005) Fat Distribution Is Strongly Associated with Plasma Glucose Levels and Diabetes in Thai Adults-The InterASIA Study. Diabetologia, 48, 657-660. https://doi.org/10.1007/s00125-005-1677-7

[6] Roth, G.A., Fihn, S.D., Mokdad, A.H., Aekplakorn, W., Hasegawa, T. and Lim, S.S. (2011) High Total Serum Cholesterol, Medication Coverage and Therapeutic Control: An Analysis of National Health Examination Survey Data from Eight Countries. Bulletin of the World Health Organization, 89, 92-101. https://doi.org/10.2471/BLT.10.079947

[7] National Health Security Office (2010) Annual Report 2009. National Health Security Office, Bangkok, Thailand.

[8] Garg, C.C. and Evans, D.B. (2011) What Is the Impact of Non-Communicable Diseases on National Health Expenditures: A Synthesis of Available Data. Discussion Paper No. 3, World Health Organization, Geneva.

[9] Moleerergpoom, W., Kanjanavanit, R., Jintapakorn, W. and Sritara, P. (2007) Costs of Payment in Thai Acute Coronary Syndrome Patients. Journal of the Medical Association of Thailand, 90, 21-31.

[10] Thanapop, S., Pannarunothai, S. and Chongsuvivatwong, V. (2009) Profile of Hospital Charges for Chronic Conditions by Health Status and Severity Level: A Case Study of 4 Provinces in Thailand. Asia Pacific Journal of Public Health, 21, 196-204.

[11] Leartsakulpanitch, J., Nganthavee, W. and Salole, E. (2007) The Economic Burden of Smoking-Related Disease in Thailand: A Prevalence-Based Analysis. Journal of the Medical Association of Thailand, 90, 1925-1929. https://doi.org/10.1177/1010539509331593

[12] Pitayatienanan, P., Butchon, R., Yothasamut, J., Aekplakorn, W., Teerawattananon, Y., Suksomboon, N. and Thavorncharoensap, M. (2014) Economic Costs of Obesity in Thailand: A Retrospective Cost-of-Illness Study. BMC Health Services Research, 14, 146. https://doi.org/10.1186/1472-6963-14-146

[13] Archongka, Y., Manimmanakorn, N., Kuptniratsaikul, V., Solunda, S. and Yee, P. (2008) Unit Cost of Stroke Rehabilitation. Medical Journal of the Medical Association of Thailand, 91, 1257-1262.

[14] Riewpaiboon, A., Riewpaiboon,W., Ponsoongnern, K. and Van den Berg, B. (2009) 
Economic Valuation of Informal Care in Asia: A Case Study of Care for Disabled Stroke Survivors in Thailand. Social Science \& Medicine, 69, 648-653. https://doi.org/10.1016/j.socscimed.2009.05.033

[15] World Health Organization. International Classification of Diseases, 11th Revision (ICD-11).

[16] StataCorp, L.P. (2011) STATA: Data Analysis and Statistical Software 12. http://www.stata.com/

[17] Tang, C.H., Chuang, P.Y., Chen, C.A. and Fang, Y.C. (2014) Medical Costs of Cardiovascular Diseasesin Taiwan. The Value in Health, 17, A759-A760. https://doi.org/10.1016/j.jval.2014.08.251

[18] Brouwer, E.D., Watkins, D., Olson, Z., Goett, J., Nugent, R. and Levin, C. (2015) Provider Costs for Prevention and Treatment of Cardiovascular and Related Conditions in Low-and-Middle-Income Countries: A Systematic Review. BMC Public Health, 15, 1183. https://doi.org/10.1186/s12889-015-2538-z

[19] Kankeu, H.T., Saksena, P., Xu, K. and Evans, D.B. (2013) The Financial Burden from Non-Communicable Diseases in Low-and-Middle-Income Countries: A Literature Review. Health Research Policy and Systems, 11, 31.

https://doi.org/10.1186/1478-4505-11-31

[20] Mogyorosy, Z. and Smith, P. (2005) The Main Methodological Issues in Costing Health Care Services: A Literature Review.

[21] Wei, J.W., Heeley, E.L., Jan, S., Huang, Y., Huang, Q., Wang, J.G., Cheng, Y., Xu, E., Yang, Q., Anderson, C.S. and China QUEST Investigators (2010) Variations and Determinants of Hospital Costs for Acute Stroke in China. PLoS ONE, 5, e13041. https://doi.org/10.1371/journal.pone.0013041

[22] Khealani, B.A., Javed, Z.F., Syed, N.A., Shafqat, S. and Wasay, M. (2003) Cost of Acute Stroke Care at a Tertiary Care Hospital in Karachi, Pakistan. Journal of Pakistan Medical Association, 53, 552-555.

[23] Ilesanmi, O.S., Ige, O.K. and Adebiyi, A.O. (2012) The Managed Hypertensive: The Costs of Blood Pressure Control in a Nigerian Town. Pan African Medical Journal, $12,96$.

[24] Le, C., Zhankun, S., Jun, D. and Keying, Z. (2012) The Economic Burden of Hypertension in Rural South-West China. Tropical Medicine \& International Health, 17, 1544-1551. https://doi.org/10.1111/j.1365-3156.2012.03087.x

[25] Ngalesoni, F., Ruhago, G., Norheim, O.F. and Robberstad, B. (2014) Economic Cost of Primary Prevention of Cardiovascular Diseases in Tanzania. Health Policy and Planning, 30, 875-884. https://doi.org/10.1093/heapol/czu088

[26] Trop, M. (2009) Financier de la prise en charge des urgences cardiovasculaires au Centre Hospitalier et Universitaire de Brazzaville. Médecine Tropicale, 69, 45-47.

[27] Kothari, A., Sagar, V., Ahluwalia, V., Pillai, B.S. and Madan, M. (2009) Costs Associated with Hospital-Acquired Bacteraemia in an Indian Hospital: A Case-Control Study. Journal of Hospital Infection, 71, 143-148.

https://doi.org/10.1016/j.jhin.2008.10.022 